\title{
The apt use of symphysio - fundal height chart during antenatal follow up: A multicenter audit
}

\author{
Palihawadana $\mathrm{TS}^{1,2}$, Wasalthilaka $\mathrm{C}^{2}$, Dias $\mathrm{T}^{1,2}$
}

\section{INTRODUCTION}

Identification of fetuses at risk of adverse perinatal outcome is an important aspect of antenatal care. Presence of a small for gestational age (SGA) fetus is known to be closely associated with poor pregnancy outcome. It is diagnosed by detection of an estimated fetal weight on ultrasound that falls below the 10th centile for that gestational age ${ }^{1}$. Since serial growth measurements cannot be done in all pregnancies, risk identification is used to select women to offer such close fetal surveillance. Early detection of SGA and timely interventions and delivery has shown to improve perinatal outcome.

Antenatal risk assessment is recommended by the royal college of obstetricians and gynaecologists (RCOG) to identify those with a high risk for SGA ${ }^{2}$. Another approach is to offer measurement of the symphysiofundal height (SFH) to identify those with fetal growth abnormalities. Population normograms are used in many settings to identify abnormalities and they have limited sensitivity in detecting growth abnormalities of the fetus $^{3}$. Customized charts are gaining more popularity due to its higher predictability of adverse perinatal outcome $^{4}$. However, in the absence of such customized charts, use of population normograms to plot serial $\mathrm{SFH}$ measurements offer the best detection rates. Such screening from 24 weeks onwards is recommended by National Institute of Clinical

1 Department of Obstetrics \& Gynaecology, University of Kelaniya.

2 North Colombo Teaching Hospital, Ragama

\section{Correspondence: Dr. T D Dias}

E-mail: thiran_dias@yahoo.com

Competing interests: None
Excellence (NICE) in their clinical guideline on routine antenatal care ${ }^{5}$.

The correct technique of obtaining a measurement in SFH will minimise the intra-observer and inter-observer variations ${ }^{6}$. This is most often useful in prediction of impaired fetal growth rather than excessive growth. With a well-followed procedural protocol it is estimated to have a specificity up to $94 \%$ for a SGA fetus. However, the sensitivity of it is lower and range between $27 \%$ to $84 \%(3)$. Despite these limitations, SFH measurement is still recommended in most of the international guidelines as well as antenatal care packages. The sensitivity and specificity of the use of $\mathrm{SFH}$ measurement can be improved by plotting the measurements in a customized growth chart during every antenatal visit that will allow detection of abnormal growth patterns ${ }^{7}$. A SFH chart is available in the antenatal data sheet used in antenatal care provided by the family health bureau (FHB). The attending health care worker is expected to measure and chart SFH during each antenatal clinic visit. However, it is observed in clinical practice that adherence to this recommendation

\begin{tabular}{|c|c|c|c|c|}
\hline & Place & Type of hospital & $\begin{array}{c}\text { Number of } \\
\text { subjects }\end{array}$ & $\%$ \\
\hline 1. & Ampara & DGH & 55 & $10.04 \%$ \\
\hline 2. & Badulla & DGH & 136 & $24.82 \%$ \\
\hline 3. & CSHW, Colombo & $\mathrm{TH}$ & 37 & $6.75 \%$ \\
\hline 4. & Hambanthota & $\mathrm{BH}$ & 84 & $15.33 \%$ \\
\hline 5. & Jaffna & $\mathrm{TH}$ & 84 & $15.33 \%$ \\
\hline 6. & Kilinochchi & DGH & 34 & $6.20 \%$ \\
\hline 7. & Ragama & $\mathrm{TH}$ & 60 & $10.95 \%$ \\
\hline \multirow[t]{2}{*}{8.} & Trincomalee & DGH & 58 & $10.58 \%$ \\
\hline & Total & & 548 & \\
\hline
\end{tabular}

is suboptimal. We conducted a snap audit in several parts of Sri Lanka to study the proportion of measurements plotted in the chart provided. The varying levels of the usage of the chart included plotting SFH measurement in the standard chart provided by FHB at all antenatal visit from 24 weeks of gestation (Completely marked), in some of the visits (Incompletely marked) or in none of the visits (Not marked). Desired goals were set at 'completely marked' in at least $80 \%$ records and 'not marked' in none of the antenatal records.

\section{METHODS}

The audit was conducted as a snap audit among all women who delivered at the selected state hospitals. Those who had regular routine growth scans for any indication and those who delivered prior to completed 34 weeks of gestation were excluded. The data collection was done following delivery prior to women being discharged from the hospital. Eight state hospitals were selected by a convenience sampling method. These included hospitals in eight districts (out of a total of 25) in 6 provinces (out of a total of 9). A paper 


\begin{tabular}{|llcccc|}
\hline \multicolumn{5}{|c|}{ Table 2. The proportion of women with different levels of marking in the SFH chart at } \\
different study centers \\
\hline Place & $\begin{array}{c}\text { Completely } \\
\text { marked }\end{array}$ & $\begin{array}{c}\text { Incompletely } \\
\text { marked }\end{array}$ & Not marked & Total \\
\hline 1. & DGH Ampara & $12(21.8 \%)$ & $13(23.6 \%)$ & $30(54.5 \%)$ & 55 \\
\hline 2. & DGH Badulla & $73(53.7 \%)$ & $36(26.5 \%)$ & $27(19.9 \%)$ & 136 \\
\hline 3. & TH CSHW, Colombo & $04(10.8 \%)$ & $07(18.9 \%)$ & $26(70.3 \%)$ & 37 \\
\hline 4. & BH Hambanthota & $62(73.8 \%)$ & $21(25.0 \%)$ & $01(1.2 \%)$ & 84 \\
\hline 5. & TH Jaffna & $15(17.9 \%)$ & $49(58.3 \%)$ & $20(23.8 \%)$ & 84 \\
\hline 6. & DGH Kilinochchi & $11(32.4 \%)$ & $20(58.8 \%)$ & $03(8.8 \%)$ & 34 \\
\hline 7. & TH Ragama & $42(70.0 \%)$ & $18(30.0 \%)$ & $0(0 \%)$ & 60 \\
\hline 8. & DGH Trincomalee & $15(25.9 \%)$ & $18(31.0 \%)$ & $25(43.1 \%)$ & 58 \\
\hline & Total & $\mathbf{2 3 4 ( 4 2 . 7 \% )}$ & $\mathbf{1 8 2 ( 3 3 . 2 \% )}$ & $132(24.1 \%)$ & 548 \\
\hline
\end{tabular}

We could not find any previous studies done in the country to study this area to make comparisons. Considering the way it is designed, the chart will be most useful in detection of growth abnormalities if serial measurements are plotted since it will allow detecting abnormalities in pattern of growth rather than at one point of time.

The audit demonstrated the use of the symphysio-fundal height chart at present is unsatisfactory. Except in three study centers, the chart was filled unsatisfactorily in a majority of pregnant women. Since SGA is a main preventable cause of intrauterine fetal

based data collection tool was used for data collection and the numbers were recoded as chart completely marked, incompletely marked and not marked at all. Data from all the centers were centrally compiled and analyzed, and are expressed as percentages.

\section{RESULTS}

The medical records of 548 patients, in eight obstetric units of eight hospitals were reviewed. The distribution of the total study sample between hospitals is shown in table 1 . The distribution of the sample according to level of marking of the SFH chart is shown in table 2 .

Of the total study population approx $42.7 \%$ women had their charts completely marked while it was incompletely marked in $33.2 \%$ and not marked in $24.1 \%$ of women. This is shown in figure

It was demonstrated that Hambanthota had the highest proportion of women with completed charts followed by Ragama and Badulla. Women who delivered at Castle street hospital for women, Colombo followed by Ampara had the highest proportion of women with charts that were not marked at all. This data is presented in a graphical format in figure 2.

\section{DISCUSSION}

This snap audit was carried out with an aim to evaluate our current usage of the symphysio-fundal height charts provided in the antenatal care record.
Figure 1. The percentage distribution of the stduy population according to level of completion in the symphysio-fundal height chart

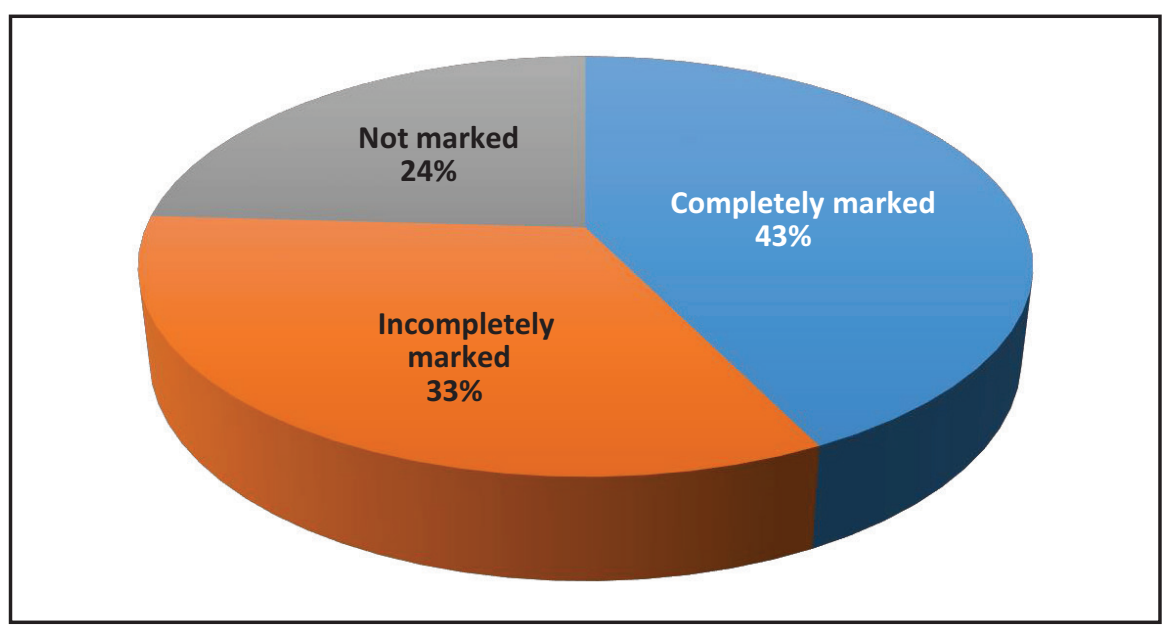

Figure 2. The percentage distribution of the study population by the level of SFH chat completion in different hospitals

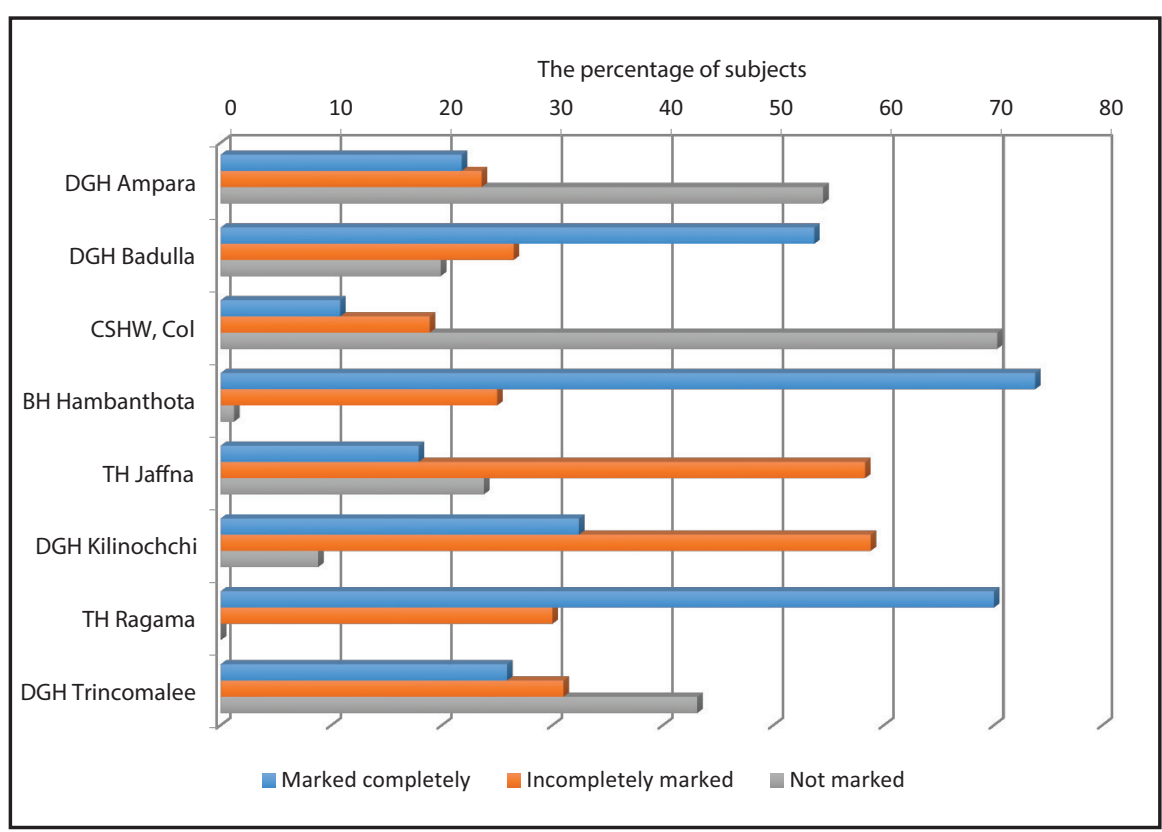


demise, there should be emphasis on detection of growth abnormalities with use of this chart. This chart is expected to be filled by the health care professional that attends to a woman at an antenatal visit. Since the community midwife manages many of these visits, it is often their responsibility to maintain the chart appropriately. Therefore, the findings of this audit do not reflect the quality of care provided at the study centers but of the primary health care services around them.

Measuring of SFH is a simple clinical procedure, which requires neither advanced skill nor equipment. Yet it seems that this task is not undertaken properly, likely due to ignorance of the importance of this simple intervention. The reasons for nonusage of the charts must be explored in further studies and necessary action should be taken to improve its use.

\section{CONCLUSION}

The use of the symphyiso-fundal height chart in the antenatal care record is unsatisfactory and do not meet the desired standards. Even when it is used, it has not been used appropriately with regular markings, which improves the sensitivity. The reasons for not using the chart should be explored and measures should be undertaken to improve its use.

\section{ACKNOWLEDGEMENTS}

Dr. Silumini Thennakoon, Consultant Obstetrician \& Gynaecologist, Ampara, Sri Lanka.

Dr. Kapila Vithanachchci, Consultant Obstetrician \& Gynaecologist, Badulla, Sri Lanka.

Dr. M Akbar, Consultant Obstetrician \& Gynaecologist CSHW, Colombo, Sri Lanka.

Dr. Prasad Wickramasinghe, Consultant Obstetrician \& Gynaecologist, Hambanthota, Sri Lanka.

Dr. K Muhundan, Consultant Obstetrician \& Gynaecologist, Jaffna , Sri Lanka.

Dr. S Sarawanabhavan Consultant Obstetrician \& Gynaecologist, Kilinochchi, Sri Lanka.

Dr. R Prathapan Consultant Obstetrician \& Gynaecologist, Trincomalee, Sri Lanka.

\section{REFERENCES}

1. Alberry M, Soothill P. Management of fetal growth restriction. Arch Dis Child Fetal Neonatal Ed. 2007; 92(1):F62-7.

2. Royal College of Obstetricians and Gynaecologists. The Investigation and Management of the Small-forGestational-Age Fetus. 2013 RCOG press, London.

3. Persson B, Stangenberg M, Lunell NO, Brodin U, Holmberg NG, Vaclavinkova V. Prediction of size of infants at birth by measurement of symphysis fundus height. $\mathrm{Br} J$ Obstet Gynaecol. 1986; 93(3):206-11.

4. Figueras F, Figueras J, Meler E, Eixarch E, Coll O, Gratacos E, et al. Customised birthweight standards accurately predict perinatal morbidity. Arch Dis Child Fetal Neonatal Ed. 2007; 92(4):F277-80.

5. National Institute for Health and Clinical Excellence. NICE clinical guideline 62: Antenatal care. 2010 Manchester, UK.

6. Morse K, Williams A, Gardosi J. Fetal growth screening by fundal height measurement. Best Pract Res Clin Obstet Gynaecol. 2009 Dec;23(6):809-18.

7. Clausson B, Gardosi J, Francis A, Cnattingius S. Perinatal outcome in SGA births defined by customised versus population-based birthweight standards. BJOG:An international journal of O\&G. 2001 Aug;108(8):830-4 